\title{
Correction to: Meta-analysis for the value of colchicine for the therapy of pericarditis and of postpericardiotomy syndrome
}

Leon L. Lutschinger ${ }^{1 \dagger}$, Angelos G. Rigopoulos ${ }^{2 \dagger}$, Peter Schlattmann ${ }^{3}$, Marios Matiakis ${ }^{2}$, Daniel Sedding ${ }^{2}$, Paul Christian Schulze ${ }^{1}$ and Michel Noutsias ${ }^{1,2^{*}}$

\section{Correction to: BMC Cardiovasc Disord (2019) 19:207 https://oi.org/10.1186/s12872-019-1190-4}

After publication of the original article [1], we were notified that an author's name is not complete.

Christian Schulze's full name is Paul Christian Schulze.

The original article has been corrected.

\begin{abstract}
Author details
'Department of Internal Medicine I, Division of Cardiology, Pneumology, Angiology and Intensive Medical Care, University Hospital Jena, Friedrich-Schiller-University Jena, Jena, Germany. ${ }^{2}$ Mid-German Heart Center, Department of Internal Medicine III (KIM III), Division of Cardiology, Angiology and Intensive Medical Care, University Hospital Halle, Martin-Luther-University Halle-Wittenberg, Ernst-Grube-Strasse 40, D-06120 Halle (Saale), Germany. ${ }^{3}$ Institute of Medical Statistics, Informatics and Data Science (IMSID), University Hospital Jena, Friedrich-Schiller University Jena, Jena, Germany.
\end{abstract}

Published online: 18 October 2019

\section{Reference}

1. Lutschinger $L L$, et al. Meta-analysis for the value of colchicine for the

therapy of pericarditis and of postpericardiotomy syndrome. BMC

Cardiovasc Disord. 2019;19:207. https://doi.org/10.1186/s12872-019-1190-4.

\footnotetext{
* Correspondence: michel.noutsias@uk-halle.de

${ }^{\dagger}$ Leon L. Lutschinger and Angelos G. Rigopoulos contributed equally to this work.

'Department of Internal Medicine I, Division of Cardiology, Pneumology, Angiology and Intensive Medical Care, University Hospital Jena, Friedrich-Schiller-University Jena, Jena, Germany

${ }^{2}$ Mid-German Heart Center, Department of Internal Medicine III (KIM III), Division of Cardiology, Angiology and Intensive Medical Care, University Hospital Halle, Martin-Luther-University Halle-Wittenberg, Ernst-Grube-Strasse 40, D-06120 Halle (Saale), Germany

Full list of author information is available at the end of the article
}

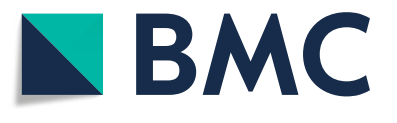

(c) The Author(s). 2019 Open Access This article is distributed under the terms of the Creative Commons Attribution 4.0 International License (http://creativecommons.org/licenses/by/4.0/), which permits unrestricted use, distribution, and reproduction in any medium, provided you give appropriate credit to the original author(s) and the source, provide a link to the Creative Commons license, and indicate if changes were made. The Creative Commons Public Domain Dedication waiver (http://creativecommons.org/publicdomain/zero/1.0/) applies to the data made available in this article, unless otherwise stated. 